\title{
THEODORO SAMPAIO E A GEOGRAFIA: ESBOÇO DE UMA HISTÓRIA CONTEXTUAL DE SUA TRAJETÓRIA E PRODUÇÃO TÉCNICO-CIENTÍFICA
}

\section{THEODORO SAMPAIO AND GEOGRAPHY: SKETCH OF A CONTEXTUAL HISTORY OF HIS TRAJECTORY AND TECHNICAL-SCIENTIFIC PRODUCTION}

\author{
Marcus Henrique Oliveira de Jesus ${ }^{1}$ \\ ${ }^{1}$ Universidade Federal de Sergipe (UFS), São Cristóvão, SE, Brasil
}

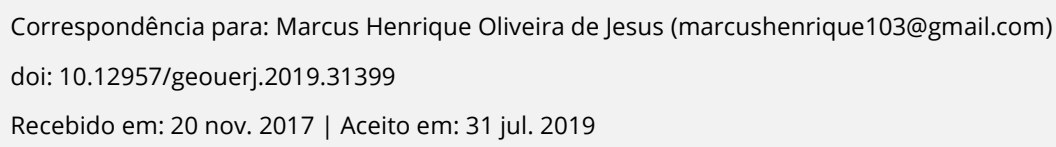

\section{RESUMO}

A História da Geografia atualmente vem recebendo consideráveis contribuições que revelam as produções e personagens de períodos anteriores a institucionalização universitária da disciplina, o que se dá a partir da implantação da Universidade de São Paulo (USP). Nosso objetivo neste trabalho é contribuir com um esboço sobre a trajetória e produção técnico-científica do engenheiro-geógrafo Theodoro Sampaio, autor de extensa produção científica e fomentador de projetos e instituições, aspectos que pensamos ser fundamentais para a realização de uma leitura renovada da Geografia, em face da escassez de produções acerca de sua história, particularmente no período anterior às universidades no Brasil. Para a realização deste artigo realizamos uma ampla revisão bibliográfica com vistas à construção de uma narrativa capaz de destacar a participação de Theodoro Sampaio nessa história. Diante disto, consideramos necessárias revisões sobre suas obras, observando a sua importância para o levantamento de informações sobre o território, notadamente no processo de modernização urbana das cidades de São Paulo e Salvador e nas proposições sobre temáticas de interesse da ciência geográfica.

Palavras-chave: História da Geografia; Theodoro Sampaio; Engenheiro-geógrafo.

\begin{abstract}
The History of Geography has been receiving considerable contributions that reveal productions and characters of periods previous the university institutionalization of the discipline, which comes from implementation of the University of São Paulo (USP). Our objective in this paper is to contribute with a sketch about the trajectory and technical-scientific production of the engineer-geographer Theodoro Sampaio, author of extensive scientific production and developer of projects and institutions, aspects that we think are fundamental for realization of a renewed reading of Geography, in face of scarcity of productions about its history, particularly in the period before universities in Brazil. For the accomplishment of this paper we carry out a wide bibliographical revision with an aim to the construction of a narrative capable of highlighting the participation of Theodoro Sampaio in this history. In view of this, we consider necessary revisions about his productions, observing their importance for the collection of information about territory, notably in the process of urban modernization of the cities of São Paulo and Salvador and in the propositions on topics of interest of geographic science.
\end{abstract}

Keywords: History of Geography; Theodoro Sampaio; Geographer Engineer.

\section{INTRODUÇÃO}

A formulação de uma narrativa sobre a vida de um personagem na história de uma disciplina não é uma tarefa fácil, ainda mais quando o nosso objetivo circunscreve-se na tentativa de inseri-lo no fluxo histórico, demonstrando as suas contribuições centrais ao desenvolvimento dessa disciplina. É necessário 
apresentar ao leitor uma trajetória reconstituída a partir de um arranjo de fragmentos do passado visto pela ótica do presente (BENJAMIN, 1996). Por tal, nosso intuito é delinear uma trajetória intelectual e profissional do engenheiro-geógrafo baiano Theodoro Fernandes Sampaio, demonstrando sua influência no campo disciplinar da Geografia.

A construção da história da Geografia no Brasil nos últimos anos tem recebido boas contribuições, incluindo aquelas oriundas de trabalhos que têm abordado personagens, obras e feitos políticosinstitucionais anteriores ao período de criação das universidades no Brasil e da implantação de instituições que forneceram novas bases para as práticas científicas e profissionais dos geógrafos, comumente reconhecidas a partir da tríade formada nos anos 1930 pelas universidades, pela Associação dos Geógrafos Brasileiros (AGB) e pelo Instituto Brasileiro de Geografia e Estatística (IBGE).

Já a história da Geografia na Bahia é tratada, em muito, através da transmissão oral de memórias contadas entre gerações ou registradas em entrevistas por professores que participaram do desenvolvimento das práticas científicas e profissionais ligadas à disciplina no estado, especialmente em Salvador, dando origem a obras testemunhais, como, por exemplo, os registros sobre a implantação do Laboratório de Geomorfologia e Estudos Regionais, fundado por Milton Santos e Jean Tricart na Universidade da Bahia em 1959, observados nos trabalhos de Silva (2011) e Silva e Gonçalves (2011).

Este laboratório se configurou como um dos principais centros de formação de pesquisadores e produções acadêmicas na Bahia e no Brasil, tornando-se um polo de atração de estudantes locais e de outros estados da federação (SOUSA, 2015). Todavia, a despeito desses importantes registros, até pouco tempo não havia pesquisas que expusessem e analisassem com maior rigor os personagens, obras e instituições antecedentes ao Laboratório de Geomorfologia e Estudos Regionais. Conforme sugere o professor Paul Claval (2013, p. 17), "Para alcançar tais resultados, convém passar da memorização espontânea, geralmente oral, a uma abordagem organizada e crítica”.

Este tem sido o mote do projeto História da Geografia na Bahia: do Periodo Regencial à República, coordenado pelo professor André Nunes de Sousa, no âmbito do Departamento de Geografia do Instituto 
Federal da Bahia (IFBA), colaborando com a compreensão dos processos formadores da disciplina no estado da Bahia e suas influências em escala nacional, preenchendo lacunas na história do desenvolvimento científico, pedagógico e institucional da Geografia em nosso país (SOUSA, 2016; 2017a; 2017b; VAZ, 2017).

Em artigo publicado por Sousa (2016), observamos o autor construir uma análise sobre as centralidades acadêmicas no Brasil, articuladas às centralidades regionais, em um recorte temporal que se estende de 1870 a 1970. Nesse trabalho, particularmente, o autor aborda a Geografia realizada anteriormente ao período de institucionalização acadêmico-universitária no país, dando destaque às práticas científicopedagógicas de professores da disciplina ao longo do Brasil Império e da Primeira República.

Diante do exposto, o intento deste trabalho é assim justificado por três aspectos em relação à historiografia da Geografia: (1) a escassez de estudos pré-institucionalização universitária da Geografia, pois, a despeito de trabalhos como os de Sousa (2016; 2017a), Cardoso (2013; 2016; 2017), e outros, a bibliografia ainda se encontra aquém de expressar o extenso volume das produções anteriores à terceira década do século XX no Brasil; (2) a necessidade de contextualização das "geografias" realizadas fora dos principais centros econômicos e políticos do país; e (3) a necessidade de construção de uma história mais aberta sobre o desenvolvimento da Geografia na Bahia e no Brasil, sistematizando distintas contribuições para o seu desenvolvimento científico, pedagógico e institucional.

Nessa perspectiva, nosso intuito é, portanto, dar destaque às ações do engenheiro-geógrafo baiano Theodoro Sampaio, atentando para suas principais contribuições em termos de pesquisas e planejamento espacial, bem como sua participação institucional em sociedades e congressos de Geografia, além de produções científicas. Como será visto, Theodoro Sampaio é um personagem de grande influência na constituição do campo disciplinar geográfico, embora, devido à sua versatilidade profissional e erudição, também já tenha sido objeto de pesquisa em outras áreas do conhecimento.

Todavia, no tocante à Geografia, são poucas as referências às contribuições técnico-científicas e institucionais de Theodoro Sampaio. Uma exceção relevante é o artigo de Caroline Bulhões Nunes Vaz 
(2017), que destaca a participação ativa do engenheiro-geógrafo baiano como presidente do $5^{0}$ Congresso Brasileiro de Geografia, realizado em setembro de 1916 na cidade do Salvador, ocasião na qual apresentou sete memórias ${ }^{1}$ de cunho geográfico.

Por fim, cabe mencionar que a construção deste trabalho foi pautada em uma ampla revisão bibliográfica e documental que possibilitou uma abordagem contextual (BERDOULAY, 2003). A partir de bibliografias e documentos obtidos, realizamos um esboço de reconstrução da trajetória intelectual e profissional de Theodoro Sampaio, tomado aqui como um esforço inicial, inserido no bojo da construção de um discurso aberto acerca da História da Geografia na Bahia e na análise da participação de personagens e obras no desenvolvimento da ciência geográfica no Brasil.

\section{HISTÓRIA DA GEOGRAFIA: UMA VIAGEM AO PASSADO PARA O (RE)CONHECIMENTO DE SABERES E FAZERES}

Neste tópico buscamos a construção de um referencial teórico-conceitual que possa auxiliar na análise da História da Geografia, pondo-o no âmbito dos debates travados sobre as incursões ao passado e a necessidade de (re)construção de um fluxo histórico capaz de incluir as contribuições institucionais, científicas e pedagógicas anteriores ao período de institucionalização universitária da Geografia no Brasil. O período que se inicia com os cursos universitários de Geografia no país é tratado, neste trabalho, seguindo as premissas de Sá (2006), como um remate no fluxo histórico da disciplina e em sua tradição de pesquisa, e não como o seu marco originário.

Inicialmente, apresentamos uma breve distinção entre os subcampos História do Pensamento Geográfico e História da Geografia, apesar de compreender que ambos estão imbricados e que, grosso modo, o segundo pode ser considerado parte do primeiro. A História da Geografia abrange as trajetórias intelectuais, institucionais e produções técnico-científicas da Geografia acadêmico-universitária ou dela

\footnotetext{
${ }^{1}$ Memória era o nome do modelo de comunicação científica apresentado em congressos e que eram publicadas nos anais dos eventos. No artigo produzido por Caroline Vaz (2017) é realizado uma análise dessas produções divulgadas por Sampaio durante o $5^{0}$ Congresso Brasileiro de Geografia.
} 
tributárias, já a História do Pensamento Geográfico, segundo a visão de Moraes (2005a), refere-se aos "conjuntos de discursos a respeito do espaço que substantivam as concepções que uma dada sociedade, num momento determinado, possui acerca do seu meio (desde o local ao planetário) e das relações com ele estabelecidas" (MORAES, 2005a, p. 32).

Portanto, a análise dos pensamentos e práticas espaciais de uma determinada sociedade ao longo do seu movimento de realização histórica, também se circunscreve como incursão em uma História do Pensamento Geográfico, visto que essas concepções são (re)criadas por sujeitos, instituições e comunidades. E, nesses termos, fazer a história de uma disciplina como a Geografia exige, também, a compreensão sobre a influência dos pensamentos em circulação no meio social e intelectual contemporâneos aos sujeitos em análise.

Por muito tempo, a ideia de "vazio científico" no Brasil foi algo amplamente disseminado, compreendendo todo o período anterior à criação das universidades na década de 1930. Trata-se de uma perspectiva explicitada, por exemplo, na concepção de ciência de José Verissímo da Costa Pereira, ao escrever um capítulo sobre a historiografia da ciência geográfica no país entre o século XVI e meado do XX, publicado no clássico livro As ciências no Brasil, de Fernando de Azevedo (1994).

O que se evidencia nesse escrito é uma concepção eurocêntrica de ciência, onde o desenvolvimento da ciência no Brasil estava vinculado às contribuições de estrangeiros em áreas diversas como botânica, zoologia, mineralogia e geologia. Essa visão foi compartilhada por muitos outros autores que, posteriormente, realizaram incursões na historiografia da ciência geográfica no país, conforme aponta Cardoso (2013).

Trata-se, desse modo, de uma história internalista e linear do que supostamente deu certo, cuja periodização se inicia a partir do ano de 1934, com a criação da Universidade de São Paulo (USP) (SOUSA NETO, 2000). Concordamos com Cardoso (2013) de que a ideia do surgimento de uma Geografia universitária só pode ser pensada evidentemente a partir da década de 1930, todavia, é 
importante destacar, conforme ainda aponta a autora, que a Geografia era realizada, em termos científicos, muitas décadas antes.

Os trabalhos de Mary (2010), Guimarães (2011), Cardoso (2013) e Sousa (2015, 2016, 2017a) evidenciam que as contribuições de algumas agremiações científicas ao desenvolvimento da Geografia no Brasil são inquestionáveis, tal como, posteriormente, o papel dos intelectuais franceses na implantação das universidades brasileiras. Neste caso, Luciene Cardoso propõe

[...] examinar determinados espaços, que de uma maneira ou de outra, contribuíram para o desenvolvimento e fortalecimento de determinadas práticas científicas e culturais, contribuindo para a institucionalização das ciências no Brasil. Muitas análises priorizam a constituição de um campo científico, ignorando a contribuição de intelectuais diletantes, tais como aos que pertenciam à Sociedade de Geografia. (CARDOSO, 2013, p. 24).

É importante frisar que o trabalho de Cardoso (2013), trata da construção de uma história social acerca da Sociedade de Geografia do Rio de Janeiro (SGRJ) entre 1883 e 1945. Essa agremiação, também conhecida como Casa Paranaguá, participou ativamente da criação do Conselho Nacional de Geografia e de sua implantação, assim como na promoção dos Congressos Brasileiros de Geografia, além da representação do país em eventos científicos internacionais.

O processo de institucionalização universitária das ciências no Brasil, e particularmente da Geografia, deve assim ser entendido como uma "inflexão" no fluxo histórico de uma tradição de pesquisas preexistentes. $\mathrm{Ou}$

[...] como o remate do processo de especialização dos saberes e da individualização crescente das disciplinas, e não como seu nascimento. Representam, na verdade, a enorme relevância que essas especializações já possuíam no âmbito da atividade científica brasileira (SÁ, 2006, p. 16).

O que diferencia a ciência acadêmico-universitária daquela praticada em instituições e comunidades científicas anteriores à primeira é a variedade de modos de "produzir ideias no país" (ibidem, p. 16), sendo presente na agenda da nova vertente, a defesa da especialização intelectual como garantia de "prosperidade do trabalho científico brasileiro e a sua equiparação internacional" (ibidem, p. 16). 
Ainda sobre esse tema, lembramos o texto de Moraes (1991) sobre a relação entre o processo de formação da identidade nacional e institucionalização da Geografia no Brasil. Nesse trabalho é destacada a centralidade da dimensão espacial na formação do Estado brasileiro, e como essa questão poderia subsidiar uma "[...] disseminação do discurso geográfico e uma rápida institucionalização da geografia" (MORAES, 1991, p. 170). De fato, o que se observou foi a temática geográfica ganhando lugar nas comunidades científicas, com alusões à teoria da Geografia em contexto internacional. Todavia, a implantação de cursos universitários, contraditoriamente, não se realizou.

Uma hipótese, talvez, seja o fato de a formação territorial brasileira, precisamente no conteúdo social do espaço, ter apresentado uma lógica particular de assimilação das forças produtivas, na qual a ausência de universidades em nosso país talvez esteja relacionada ao trabalho compulsório através da escravidão. Com a modernização do Estado e do território, nos dois primeiros quartéis do século XX, observamos que as condições objetivas (econômicas, sobretudo) se diversificaram rapidamente, impulsionando uma maior especialização do trabalho (agora assalariado) e das disciplinas e, consequentemente, o processo de institucionalização de universidades.

Nessa nova conjuntura, a comunidade de geógrafos acadêmico-universitária fez da Universidade seu locus de produção e legitimação, lutando, segundo Moraes (1991, p. 172), contra "o ensaísmo dominante, destituído de 'rigor empírico' da 'ciência'” e ocuparam cargos técnico-administrativos nos órgãos de planejamento nascentes, fornecendo subsídios as ações estatais, optando por não se expor aos debates sobre as questões nacionais (PEREIRA, 2000).

No entanto, novos estudos acerca da atuação das comunidades geográficas existentes no Brasil, na transição entre os séculos XIX e XX, demonstram que muitos trabalhos produzidos no país denotavam preocupação com um caráter científico, seguindo as premissas da Geografia realizada na Europa. Um exemplo emblemático dessa questão são as monografias regionais descritivas elaboradas para o $5^{0}$ Congresso Brasileiro de Geografia, de 1916, em Salvador, produzidas com rigor científico e empírico, sistematizando informações sobre vários municípios baianos, conforme descrevem Sousa (2017a) e Baumgartner (2017). Destacava-se, nesse período, a necessidade de uma produção científica amparada 
em um rigor de método, ultrapassando os modos de fazer Geografia do passado. A influência do romantismo alemão na construção dos materiais didáticos no final do século XIX na Bahia passou a ser substituída por um positivismo realista (SOUSA, 2017a).

Dito isto, é importante dar continuidade à apresentação da base teórico-conceitual, sobre a qual estamos trabalhando, destacando a noção de campo científico e, consequentemente, seu desdobramento na ideia de campo disciplinar, como importante instrumental analítico. O campo se refere a uma concepção de Bourdieu que já foi amplamente utilizada em outros estudos que tratam da temática da História da Geografia (MORAES, 2005b; SOUSA, 2015).

Bourdieu (2004) insere a ideia de campo como uma forma de superação das análises exclusivamente internalistas das histórias da ciência, filosofia e arte, ou seja, daquelas leituras que analisam o desenvolvimento dessas áreas sobremaneira a partir de suas produções e em oposição às abordagens externalistas, tributárias quase sempre do marxismo e que constroem suas análises a partir do contexto social em cada tempo e espaço em que se produz a ciência. Para superar a dicotomia na análise da ciência (internalismo versus externalismo), Bourdieu elaborou a noção de campo, que consiste precisamente em um

\footnotetext{
[...] universo no qual estão inseridos os agentes e as instituições que produzem, reproduzem ou difundem a arte, a literatura ou a ciência. Esse universo é um mundo social como os outros, mas que obedece a leis sociais mais ou menos específicas. A noção de campo está ai para designar esse espaço relativamente autônomo, esse microcosmo dotado de suas leis próprias. Se, como o macrocosmo, ele é submetido a leis sociais, essas não são as mesmas. Se jamais escapa às imposições do macrocosmo, ele dispõe, com relação a este, de uma autonomia parcial mais ou menos acentuada. (BOURDIEU, 2004 , p. 20 e 21)
}

Em síntese, o que o autor propõe é que o campo está sim sujeito às imposições externas, mas que também cria suas próprias normas dentro do seu grau de autonomia. O que se pode traduzir é que, nesse sentido, um campo não pode ficar alheio às transformações socioespaciais do mundo, mas, também, não é mero reflexo das outras esferas da vida social, sobretudo a economia e a política. No seu interior, há decisões que definem, por exemplo, quais temáticas, obras e personagens são privilegiados para discussão. 
Podemos pensar assim que o personagem a ser tratado aqui, Theodoro Sampaio, tem uma grande relevância já que participou de congressos nacionais de Geografia, tanto como presidente de um dos certames, quanto expositor de memórias, foi convidado e participou como sócio correspondente da Associação dos Geógrafos Brasileiros (AGB), foi presidente do Instituto Geográfico e Histórico da Bahia (IGHB) e sócio fundador da agremiação congênere em São Paulo, não sendo, todavia, devidamente estudado nas pesquisas da Geografia contemporânea (VAZ, 2017).

Sousa Neto (2000) constrói algumas ideias sobre a necessidade de se fazer história da ciência e de como esse processo está intrinsecamente ligado ao processo do fazer científico. 0 autor contribui com o esclarecimento de como essas construções historiográficas auxiliam na compreensão das identidades científicas. Segundo o autor, é preciso realizar assim uma história daqueles que foram colocados fora da história. Assim, mesmo existindo trabalhos relevantes sobre Theodoro Sampaio em áreas como a Arquitetura (COSTA, 2001), as Ciências Sociais (LIMA, 1981), o Desenho (COSTA, 2007), e mesmo e em menor número na Geografia (VAZ, 2017), objetivamos ao longo desse trabalho realizar uma análise eminentemente geográfica, buscando um sentido da obra e papel do autor para a Geografia.

Conforme argumenta Machado (2000), não há esgotamento de assunto, desde quando a busca das fontes e dados, tratamentos e sentidos interpretativos realizados sejam diferenciados ao ser feito pelo pesquisador. Para a autora, o que se esgota é o que fica na superfície, o que é feito a partir de cópia do que já foi realizado, sem acrescentar pesquisas originais ou informações relevantes, e a ausência de uma ideia original na cabeça acerca do assunto. Como dito nos parágrafos anteriores, Theodoro Sampaio carece de mais leituras fundamentalmente geográficas, tanto da sua obra, quanto da sua trajetória.

\section{THEODORO SAMPAIO: UMA TRAJETÓRIA INTELECTUAL A PARTIR DA FORMAÇÃO, PARTICIPAÇÃO EM INSTITUIÇÕES E PRÁTICAS PROFISSIONAIS}

No tópico anterior, demonstramos que a construção de uma história mais aberta do desenvolvimento do campo disciplinar geográfico no Brasil, capaz de agregar novas experiências e pesquisas no mesmo fluxo historiográfico, se constitui como um movimento importante para fomentar novos olhares e 
compreensões sobre a trajetória da disciplina e de seus autores fundamentais, assim como a possibilidade de combinações e/ou superações entre teorias atuais e pretéritas ${ }^{2}$. Nos próximos tópicos será exposto o nosso esboço de uma história contextual da trajetória e produção técnico-científica de Theodoro Sampaio.

\section{A busca por um método para fazer História da Geografia}

Já foi argumentado neste trabalho que uma abordagem acerca da história da ciência que contemple apenas os embates teóricos e metodológicos no interior de suas instituições, entre os cientistas que integram esse campo (perspectiva internalista) não é capaz de permitir uma análise mais substantiva sobre as trajetórias e desenvolvimentos da disciplina e de seus autores fundamentais. Também é limitada uma perspectiva unicamente externalista, vinculada tão somente aos contextos social, econômico e político que interferem na produção científica.

Avaliamos ser necessária uma integração ampla entre essas duas formas de tratamento metodológico, observando o próprio movimento interno da ciência e o contexto de transformações no mundo, lançando olhar sobre como os cientistas se comportam frente às transformações socioespaciais, e quais são suas respostas a elas. Uma assertiva colocada por Bourdieu na construção das teorias dos campos é que não existe a possibilidade de o campo científico ficar alheio a esses aspectos, sendo mais ou menos influenciado por eles. Portanto a integração apresenta-se como um horizonte rico de análise.

No tocante à construção da História da Geografia, observamos os autores se debruçarem sobre suas temáticas a partir de metodologias variadas. Alguns trabalham a partir de um encadeamento lógico da epistemologia e da história das ideias (CLAVAL, 2010), outros seguindo o rastro das estratégias das comunidades e cientistas (CAPEL, 1999; 2010); alguns lançam olhares através da história das ideias e das permanências (LIRA, 2012), ou através do método contextual (BERDOULAY, 2003), além dos que constroem histórias a partir do deslocamento e recuperação de fragmentos do passado referentes a centralidades acadêmicas, contextos, produções e influências teóricas (SOUSA, 2015; 2016; 2017a; 2017b).

\footnotetext{
${ }^{2}$ Observamos essas proposições sendo realizadas em Antunes (2017) e Baumgartner (2017), por exemplo.
} 
Avaliamos que a inserção de Theodoro Sampaio no âmbito do fluxo historiográfico da Geografia carece de uma incursão que seja capaz de gerar uma compreensão acerca do contexto de formação e atuação deste autor, já que este participa de um momento histórico particular da história do país, marcado por grandes transformações socioespaciais. Assim, suas ações e produções devem ser revisitadas à luz tanto da percepção da originalidade das suas obras e pensamentos, quanto pela contextualização do momento e espirito da época (Zeitgeist), avaliando, de certo modo, quais as influências que lhe chegam e quais ele exerce sobre outros personagens.

É importante destacar Theodoro Sampaio é um personagem central no processo de urbanização de São Paulo e de Salvador e na implantação e desenvolvimento institucional de seus institutos históricos e geográficos, onde se observa sua participação no levantamento de informações territoriais, participação em reformas sanitaristas, e planejamento urbano, sobressaindo a construção da atual sede do Instituto Geográfico e Histório da Bahia (IGHB) e outros prédios na capital baiana, além do plano de urbanização do bairro da Pituba, em Salvador, o qual seria implantado décadas depois (SANTOS, 2010).

Portanto, partindo do reconhecimento das questões apresentadas, sugerimos que esta construção historiográfica se circunscreva em um esforço de lançar bases para inserção deste sujeito na História da Geografia através de um método capaz de abarcar questões variadas que envolvem seu contexto social, observando as influências que lhe chegam e suas ações, bem como os sujeitos que também são influenciados por suas ideias e que compõe seu círculo de afinidades (BERDOULAY, 2003).

Berdoulay (2003) apresenta algumas reflexões acerca da abordagem contextual. Trata-se de ideias que são bastante interessantes para a busca de um método capaz de inserir Theodoro Sampaio na historiografia da Geografia. O primeiro aspecto é sobre a relação entre abordagens internalistas e externalistas, estas não podem ser vistas, assim como defende Bourdieu (2004), de modo dicotômico, e devem ser associadas sim de forma "continuum, sem nenhuma distinção bem definida." (BERDOULAY, 2003, p. 51). 
Os outros aspectos elencados por Berdoulay (2003) são: (a) a não consideração de uma tendência geográfica superior a outras, já que as descobertas podem demonstrar os insucessos de umas em relação a outras; (b) a necessidade de estudos sobre as questões que envolvem a sociedade de cada época, assimilando a ideia de que os sujeitos recebem influências dos pensamentos e eventos sociais, econômicos e políticos do seu momento histórico; (c) a não adoção de conceitos de "comunidades científicas" tão estreitos, já que as relações podem ser diversas, incluindo várias instituições e indivíduos que compõe o círculo de afinidade dos autores; e, (d) por último, ele destaca que o interesse não está vinculado ao uso ou demanda da ideia, já que o contexto explica " a originalidade da síntese de uma série particular de ideias sustentadas por um individuo ou um grupo, embora qualquer uma dessas ideias, tomada em separado, possa não ser nova ou inovadora" (BERDOULAY, 2003, p. 52).

Assim, nosso objetivo é a construção de uma trajetória de Theodoro Sampaio mais imbricada com o contexto socioespacial em que o autor viveu e produziu sua obra. Nesse ensejo salientamos que tal trabalho ainda se encontra por ser feito em pesquisas futuras, nosso intento aqui se insere na elaboração de um esboço capaz de lançar traços fundantes da sua história intelectual, suas ações, produções e participações em comunidades, instituições e demais processos.

\section{Theodoro Sampaio: esboço de uma trajetória dentro de um contexto social, cultural, econômico e político}

O Brasil do século XIX era um país vivenciando grandes transformações na sua história social e formação territorial. Com a chegada da família real portuguesa houve a instalação de instituições de ensino superior, como as faculdades de Direito e Medicina, a centralização política, e nos anos seguintes o país conquistou a sua emancipação política (SCHWARCZ, 1993). Após a independência do país, o império através da continuidade dinástica foi instituído como forma de governo para amenizar as questões de identidade auxiliando na construção de uma identidade nacional e legitimando a existência do Estado, conforme sinalizado por Moraes (1991). Este país já nasce com grandes fundos territoriais ainda não apropriados efetivamente, e que tem como seu leit motiv desde o passado colonial a ocupação 
do solo. Nesse sentido a conclusão da formação territorial se configura como elemento fundante da unidade da nação (MORAES, 1991).

O modelo de gestão adotado com a centralidade na figura do imperador afastava também o medo do Brasil sofrer a mesma fragmentação territorial vivenciada na América espanhola, além disso, o formato também não eliminava a participação das elites regionais e não negava as suas aspirações oligárquicas (MORAES, 1991). O Estado brasileiro recém-emancipado irá engendrar algumas ações como tentativa de dotar o território nacional de maior fluidez e integração regional, visando o atendimento das exigências do capitalismo industrial que, passo a passo, se consolidava ao longo do século XIX.

Caio Prado Júnior (2008), através da construção de uma periodização sobre a História Econômica do Brasil, demonstra que durante o período compreendido entre 1808 e 1850 houve mudanças substanciais na economia brasileira, estas que alteraram a centralidade econômica do país, levando assim o Norte a um período de estagnação. Ele destaca a emergência da monocultura cafeeira que ganha a dianteira através da sua produção no Centro-Sul, produto este que até então ocupava uma importância pequena na balança comercial brasileira. Por outro lado, o algodão e o açúcar sofrem com as mudanças no comércio internacional. No caso do açúcar são as querelas relacionadas à substituição do açúcar produzido a partir da cana de açúcar pelo da beterraba, o que gerou uma desvalorização. Já o algodão sofre com a ocorrência de novos fornecedores, sobretudo os produtores do norte da América (EUA) e os orientais, e o esgotamento das terras exploradas ao longo de mais de dois séculos (PRADO JÚNIOR, 2008).

A expansão do café, por seu turno, se beneficia com a decadência do tráfico de escravos e a cessação posterior. O Sul, emergente, resolveu seu problema da mesma natureza importando escravos do Norte, e, posteriormente, foi beneficiado com os migrantes que optaram pelo Sul e Sudeste do país. Nesse novo momento, a centralidade de produção se colocou sobre o Rio de Janeiro, que, desde estão, além de ser o centro político e administrativo do império brasileiro, também se firmou como núcleo central da produção de café, devido às qualidades das terras ao longo do seu território (PRADO JÚNIOR, 2008). 
No meio dessa conjuntura, nasceu Theodoro Fernandes Sampaio (Figura 01) em meados do século XIX, precisamente em 7 de janeiro de 1855. Nasce no Engenho de Canabrava, situado no Recôncavo Baiano, estabelecimento pertencente a Manoel Lopes da Costa e Pinto, o Visconde de Aramaré, situado no território que atualmente pertence ao município de Santo Amaro (COSTA, 2007). Trata-se de uma região que experimentou o auge da produção de açúcar no nordeste brasileiro e a sua decadência momento do nascimento de Theodoro Sampaio.

Filho de Domingas da Paixão do Carmo, escrava, supostamente com o padre Manuel Fernandes Sampaio. Talvez por ser o único filho homem de Domingas com Manuel, e seu pai ser branco, Theodoro Sampaio não se tornou escravo no engenho em que nasceu, tendo, assim, uma trajetória completamente diferente daquela que teve os seus irmãos. Conforme argumentado por Costa (2007), ele se destacou sendo negro na vigência da escravidão e vivenciou condições de branco, recebendo a melhor educação de acordo as condições da época. Segundo discorre Lima (1981), não existem muitos registros sobre a sua juventude.

Ainda criança, após concluir as letras iniciais se mudou com o suposto pai ${ }^{3}$ para São Paulo onde este assumiu a capelania na freguesia de Pinheiros, mas mudando-se rapidamente para o Rio de Janeiro, onde ingressou no Colégio São Salvador (SANTOS, 2010). Acreditamos que a migração do jovem Theodoro Sampaio junto com seu pai, saindo da Bahia para o Sudeste, pode ter sido motivada pela função profissional do pai, além da centralidade político-econômica deslocada do Nordeste para o Sudeste do país. Pois, neste momento, em Salvador já havia escolas primárias que ofertavam ensino primário e secundário, como o Lyceu Provincial da Bahia que ele poderia cursar.

\footnotetext{
${ }^{3}$ Há questões em aberto à respeito da paternidade de Theodoro Sampaio. Em sua própria autobiografia, o autor coloca Manuel Sampaio como seu progenitor. Mas outros biógrafos, já levantaram uma contenda que apontam supostamente outro individuo como suposto pai de Theodoro Sampaio, um dos donos do engenho. Em carta endereçada ao americano Donald Pierson, e arquivada no acervo do Instituto Geográfico e Histórico da Bahia (IGHB), Theodoro diz: "Nasci de paes modestos. O meu progenitor era branco, homem culto de uma família de lavradores, senhores de engenho no Recôncavo baiano" (RAMOS, 2015). Na carta, se abrem margem para computar a paternidade até ao próprio Visconde de Aramaré, porém não iremos adentrar neste mérito em nosso trabalho, apenas salientamos a existência dessa questão.
} 
Após terminar os estudos secundários no Colégio São Salvador, ingressou no Colégio Central em 1872, instituição onde começou sua formação superior em Engenharia Civil. Durante o seu curso, devido à morte do seu suposto progenitor, Theodoro começa a lecionar Geografia, História, Latim, Matemática e Filosofia nos colégios São Salvador e Ab́lio, além de dar aulas particulares, ações que irão garantir o seu sustento (COSTA, 2001). Ainda durante a sua formação superior, no quarto ano de curso, foi contratado para a realização de trabalhos gráficos no Museu Nacional que, naquele momento, o destacado geólogo norte-americano Orville Derby organizava algumas exposições. Derby era reconhecidamente um importante cientista norte-americano que havia sido contratado pelo governo imperial para a realização de trabalhos na Comissão Geológica e Mineralógica do Império do Brasil (CGMIB) sob a tutela de Charles Hartt, sendo, posteriormente, contratado para trabalhar neste museu (COSTA, 2001; LUCIO, 2014).

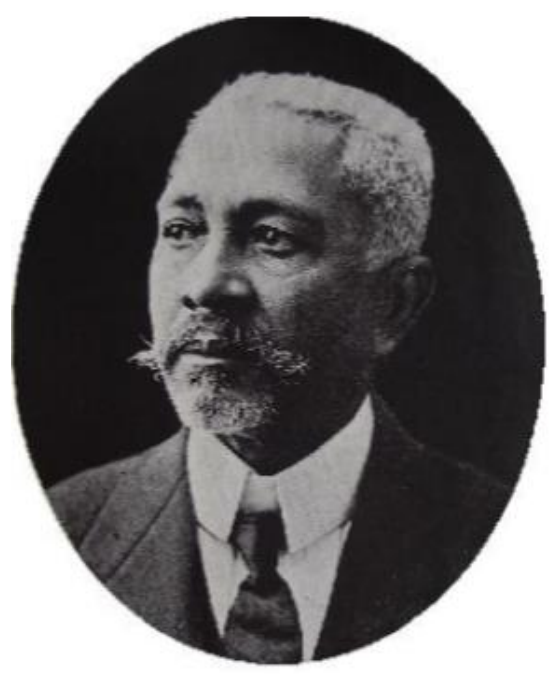

Figura 1. Theodoro Fernandes Sampaio. Fonte: COELHO, 1923 apud SILVA, 2006.

As relações estabelecidas entre Sampaio e Derby foram frutíferas, tanto que o primeiro foi indicado pelo geólogo norte-americano para compor a Comissão Geográfica e Geológica de São Paulo (CGGSP), que havia sido formada com intuito de mapear o território paulista e seus recursos. Com Derby à frente dessa comissão, Sampaio foi escolhido engenheiro-chefe responsável pela incursão ao Vale do Parapanema (LUCIO, 2014). Aqui se destaca um influente integrante do círculo de afinidades de Theodoro Sampaio, fundamental em sua trajetória profissional, afinal, a indicação de um engenheiro baiano e negro, realizada por um norte-americano, para a liderança de incursões de uma organização atrelada aos 
interesses das elites paulistas, com vistas à modernização do território para fluidez da produção do café, não poderia passar despercebido.

Ao final do século XIX, São Paulo desbancava o Rio de Janeiro e se destacava na produção da monocultura cafeeira, que avançava consideravelmente em seu território rumo ao oeste do estado. E a convergência de interesses entre empresários, fazendeiros e políticos paulistas iria resultar nessa nova necessidade de fluidez do território. Lembramos que esta Comissão inicia suas atividades em 1886, período ainda em vigor da escravidão e marcado em contextos mais amplos pelo desenvolvimento de pensamentos atrelados às teorias raciais e ao darwinismo social (SCHWARCZ, 1993).

É importante destacar que Theodoro Sampaio havia consciência das contradições inerentes ao seu momento histórico, ainda marcado profundamente pelas questões referentes à escravidão e à presença do negro na sociedade. E como um sujeito de destacada autonomia, que poderia se beneficiar da condição de "mulato" e se colocar à parte disso, ele assume sua condição, se colocando como negro e evidenciando momentos da sua trajetória em que sua cor de pele foi um impedimento para ocupação de um cargo na comissão (SANTOS, 2010). Além do mais, caminhando por esses meandros, utilizou dos meios possíveis para possibilitar aos seus irmãos cativos a liberdade, através da compra de alforria (RAMOS, 2015).

Lima (1981) exibe as notas obtidas por Theodoro Sampaio durante os cinco anos de curso de Engenharia, além de uma suposição dos aspectos relevantes em relação à carreira profissional de engenheiro civil que o levaram a optar por esta formação. Acreditamos que a possibilidade apresentada pelo autor que está amparada na demanda desses profissionais em face do processo de levantamento sistemático de informações sobre o território, da construção de infraestruturas urbanas, a implantação da navegação a vapor e construção de estradas de ferro no país, são elementos relevantes. A Escola Central se configurava como uma alternativa a forte tradição de estudos humanísticos no país, em centros como a Faculdade de Medicina e a Escola de Direito. Na visão de Lima (1981), Theodoro Sampaio havia percebido a ampliação da demanda por engenheiros e a alternativa à tradição humanística. 
Mas, após uma análise das relações das notas obtidas (Quadro 01) durante os cinco anos de graduação do engenheiro-geógrafo baiano, observamos que os resultados obtidos em Desenho sempre se destacaram, desde o início da sua formação. E como já explorado por outros autores (COSTA, 2007; LIMA, 1981), a habilidade de desenho de Theodoro Sampaio é bastante notável e impressionante, com grandes riquezas de detalhes. Aliado ao fato de um dos seus primeiros empregos está de certo modo relacionado à sua habilidade com o desenho, podemos elencar como possibilidade que ele tenha escolhido essa área também devido às aptidões particulares.

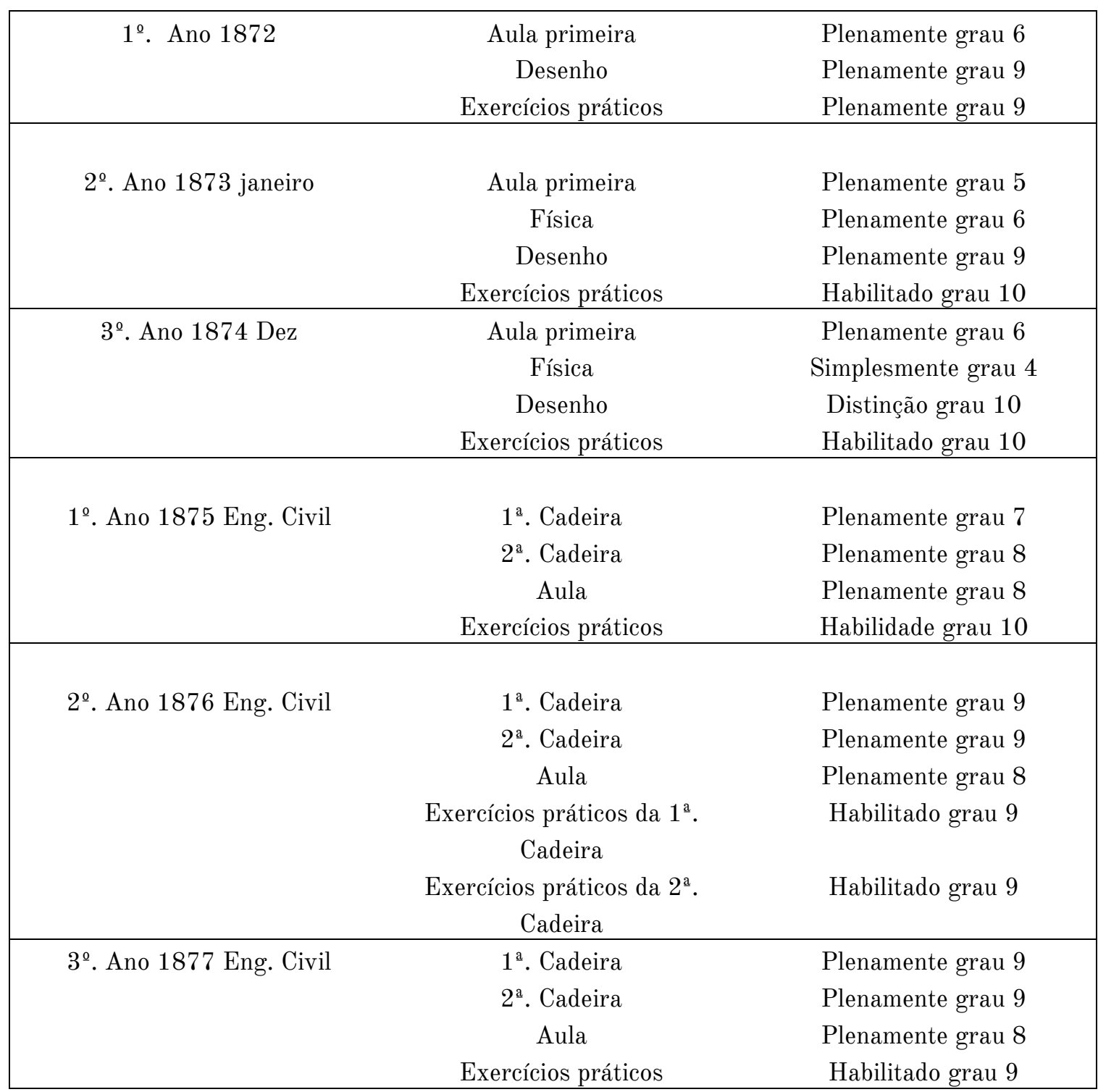

Quadro 1. Histórico Escolar de Theodoro Fernandes Sampaio. Fonte: Lima, 1981 
Apontamos aqui um aspecto importante em relação à formação de Theodoro Sampaio. Assim como ressaltado por Lima (1981), em relação à valorização da profissão de engenheiro civil durante o século XIX no Brasil, acreditamos, concordando com o autor, que isto ocorreu devido aos processos de construção de estradas de ferro, implantação da navegação a vapor e modernização de portos.

Acrescentando as ideias de Machado (2012, p. 311), "[construção] de pontes, de canais, indicam a intensificação das relações com o mercado internacional e o início da reordenação interna do território. [....] destaca-se a valorização, mesmo que lenta e problemática, das carreiras de engenharia, civil e militar". Neste sentido, esse contexto poderia ser comparado ao que ocorreu na França no início do século XIX, onde a necessidade de informação sobre o território, e a construção de mapas que foram realizadas por engenheiros geógrafos auxiliavam na modernização do poder político e no fortalecimento da administração francesa sobre o território através dessas informações (VARGAS, 2003). Observa-se uma valorização da engenharia como área especializada em levantamento de informações territoriais e produção cartográfica entre os séculos XVIII e XIX.

E neste aspecto, como podemos inserir essas práticas, em especial as de Theodoro Sampaio, no meio desse fluxo? Atentando para um quadro mundial de valorização dessa especialização, onde estratégias curriculares e de ensino foram implementadas com ênfase na potencialização da formação de engenheiros com capacidade de realizar levantamentos e construções de mapas sobre o território. Uma reforma ocorrida na França criou a Escola Politécnica, uma alternativa às antigas instituições de formação, "en ese lugar, se prepararía el camino de los alumnos para ingressar las escuelas de especialización (de aplicación), como la del ingeniero geógrafo" (VARGAS, 2003, p. 104).

Vargas (2003) também destaca a Escola de Engenheiros-Geógrafos, criada em 1809, que era responsável pela formação científica e as aplicações tanto de trabalhos de campo quanto de gabinete, com ênfase nas ciências físico-matemáticas. É destacado que a própria instituição onde Theodoro realizou sua formação superior sofreu uma série de transformações, e no início do século XIX, no ano de 1810, se transformou na Academia Real Militar, seguindo o modelo francês da Escola Politécnica de Paris (COSTA, 2007). 
A escola onde Sampaio realizou sua formação tem uma longa trajetória e tradição na formação de profissionais voltados para o que se constituiu como Engenharia. Iniciou-se com a sua fundação em 1792, sobre o nome da Real Academia de Artilharia, Fortificação e Desenho, na cidade do Rio de Janeiro, e se tornou a "precursora da linha direta e contínua da escola de Engenharia da Universidade Federal do Rio de Janeiro e do Instituto Militar de Engenharia. E, também, considerada a primeira escola de Engenharia das Américas." (OLIVEIRA, 2005, p. 4).

Segundo Oliveira (2005), anteriormente a isto, havia aulas de Fortificação, voltadas ao ensino militar que integravam também conhecimentos relacionados à engenharia, criadas através de carta régia, em 1699. Esta academia se transformou em 1810 na Escola Militar da Corte e, em 1858, se transformou na Escola Central (1858-1874), criada para o ensino de matemática, ciências físicas e naturais, assim como a doutrinação da engenharia civil (MOREIRA, 2011). E foi durante o período de transição entre Escola Central e Escola Politécnica que Theodoro Sampaio se formou. Deste modo, é importante destacar possíveis influências transmitidas para os trabalhos deste personagem e que aparecem de um modo ou de outro nas suas contribuições técnico-científicas.

O primeiro emprego de Theodoro após a conclusão do seu curso superior foi na Comissão Hidráulica do Império, de 1879 a 1880, que tinha como objetivo a proposição de obras para a melhoria de portos e para a navegação através dos rios brasileiros. A primeira ação realizada foi um estudo realizado em São Paulo sobre o porto de Santos. Além desse trabalho, também realizou levantamento de informações nos sertões do centro e nordeste do país, em específico na província onde nasceu, a Bahia. Como resultado desses trabalhos de campo, houve a publicação dos seus relatórios e do livro Rio São Francisco e a Chapada Diamantina (1906), além das publicações na revista Santa Cruz, entre 1900 e 1903 (SANTOS, 2010).

Posteriormente, começou a trabalhar como engenheiro a serviço do Prolongamento da Estrada de Ferro da Bahia ao São Francisco, em 1882, após ter rejeitado a proposta realizada pela Recife and São Franscico Railway Company, devido a oferta salarial ser baixa. Este momento marcou seu retorno à 
província natal e seu trabalho foi dedicado à elaboração de cálculos e a construção de pontes metálicas para passagem de trens a vapor (SANTOS, 2010).

Em 1883, Theodoro Sampaio foi convidado para compor a Comissão de Melhoramento do Rio São Francisco, aplicando as premissas indicadas pela Comissão Hidráulica do Império. Como resultado deste momento, o trabalho foi publicado na forma de artigo, acompanhado de uma planta, na Revista de Engenharia do Rio de Janeiro. Segundo a leitura realizada por Santos (2010), a planta publicada tem mais um caráter de mapa, já que no conteúdo de informações extrapola a ênfase na informação sobre a linha de trem, reunindo detalhamento sobre aspectos físico-naturais da região de Alagoinhas até a divisa com Sergipe.

Esses trabalhos realizados por Theodoro Sampaio denotam um período do país, onde se ensaiava de certo modo a integração produtiva através da construção de infraestrutura de circulação tanto de produtos quanto de pessoas. Suas ações, nesse sentido, devem ser vistas sobre uma ótica que destaque a importância dos trabalhos realizados por engenheiros-geógrafos no planejamento territorial para a circulação. A caderneta de campo de Theodoro Sampaio, que foi iniciada aos 22 anos durante os últimos anos de curso, registra aspectos como construção civil, de estradas de rodagem e caminhos de ferro (SANTOS, 2010), servindo como um elemento importante para a compreensão das suas ações dentro deste contexto, assim como os relatórios produzidos e as publicações resultantes.

O início das suas atividades na Comissão Geográfica e Geológica de São Paulo (CGGSP) se inicia em 1886 e vai até o período de 1892, como já informado em outro momento deste texto. A entrada do Theodoro Sampaio nessa comissão foi proporcionada através do seu vínculo com Derby, que o convidou para integrar a comissão. Durante esse momento, o engenheiro-geógrafo baiano foi responsável pela organização da Seção Geográfica e das finanças (SANTOS, 2010).

Como resultado de grande valor já apreciado por outras literaturas sugeridas por Santos (2010), há a confecção da rede geodésica de Campo Largo, considerada a pioneira do Brasil, um elemento importante na história da cartografia nacional. Sua passagem pela CGGSP foi finalizada quando nos últimos anos 
(1890 - 1892), ele iniciou trabalhos que eram estranhos à sua função, solicitando a Derby, por fim, a exoneração de suas funções (SANTOS, 2010).

As atividades que realizava ao final, anteriormente citadas, estavam, sobretudo, ligadas ao novo momento de sua trajetória sua profissional. Realizava trabalhos para a Companhia Cantareira de Águas e Esgoto, como engenheiro na Secretária do Interior. Nesse novo momento da sua vida, um novo círculo de afinidade começou a se desenhar, estabelecendo relações com Euclides da Cunha, quando esse último foi trabalhar na Superintendência de Obras, órgão integrante da Secretaria de Agricultura, Comércio e Obras Públicas de São Paulo, após licença do Exército (SANTOS, 2010).

Na Companhia Cantareira de Águas e Esgoto, como colegas, estabeleceram vínculos que se desdobram nas influências de Theodoro Sampaio sobre a produção técnico-científica e literária de Euclides da Cunha (SEVCENKO, 2002), no tocante às descrições sobre os sertões baianos, durante a empresa de Canudos. As anotações e memórias cedidas por ele ao seu novo amigo enriqueceram seu trabalho, que em publicação anterior à sua viagem, recebe elogios de Júlio Mesquita, que destaca o fato de a publicação ter uma riqueza de detalhes mesmo sem o escritor ter visitado a localidade (SANTANA, 1998; SANTOS, 2010).

Durante essa transição (saída da CGGSP), houve também a realização de um plano por Theodoro Sampaio, publicado sob o título "Viagem a Serra da Matiqueira, Campos do Jordão e São Francisco dos Campos" em 1893. Esse trabalho foi o primeiro e único financiado pelo capital privado e que marcava o planejamento territorial com vistas à construção de uma urbanização que atendesse a questões que integrassem funcionalidade e saúde (sobretudo sanitarismo) do interior paulista, se desenhando também como uma obra onde é destacado o pioneirismo de Sampaio no tocante aos aspectos urbanísticos, como na elaboração de diretrizes ecológicas, assim como uma proposição sobre o debate acerca da capital do Brasil (SANTOS, 2010). Este trabalho merece uma análise mais detalhada, uma vez que, como citado por Santos (2010), há destaque de questões que só irão aparecer décadas após, assim como se configura como um trabalho alinhado aos paradigmas positivistas e pragmáticos da época. 
Durante sua passagem por São Paulo (1892 a 1904), Theodoro participou de obras significativas à frente da chefia dos Serviços de Água e Esgoto da capital paulista, assim como durante a gestão de Bernardino de Campos, acumulou cargos de "engenheiro sanitário e consultor técnico da Secretaria do Interior, a convite de Vicente de Carvalho" (COSTA, 2016, p. 20). Neste momento, participou de obras de construção de hospitais de isolamento entre outras instituições de higiene, da elaboração de diretrizes de reestruturação da secretaria, das obras de desenvolvimento e restauração das redes de água e esgoto da cidade de São Paulo e de muitas outras. Realizou estudos de captação de água oriunda do rio Tietê, como também participou na elaboração de uma legislação sanitária, apesar que este último item não tenha documento probatório "de que o engenheiro em questão tenha escrito o referido Código, porém acreditamos que, pelo menos, Sampaio tenha participado da elaboração da Lei de 1894" (COSTA, 2016, p. 20).

Destacamos que a passagem de Theodoro pela cidade de São Paulo é marcada por um momento de transformação, aonde o que viria a ser a maior metrópole nacional dava os seus primeiros passos de inserção na modernidade ao aderir aos ideais sanitaristas como modelo de forma urbana. Como um agente integrante e profundamente envolvido, Sampaio se torna um personagem central na constituição de uma geografia histórica que constitua esse arranjo espacial de modernização da capital paulista, e também elemento chave no planejamento urbano e regional da época.

Portanto, percebe-se que aqui há um lastro para análise do papel deste engenheiro-geógrafo e a Geografia Histórica de São Paulo durante o período em transição de uma cidade que elimina através das obras urbanas os resquícios dos seus traços coloniais, como também para se examinar aspectos do planejamento urbano e regional na transição entre o Império e a República.

Ainda devemos destacar nesse momento a participação de Theodoro Sampaio na fundação do Instituto Histórico e Geográfico de São Paulo (IHGSP) em 1894, instituição onde manteve relações com Alfredo Taunay, Rodolfo Garcia e Eduardo Prado (LIMA, 1981), assim como um envolvimento nas pesquisas acerca da história e geografia de São Paulo, como também as correlacionadas aos índios, principalmente nas concernentes a língua tupi. Este último interesse resultou na elaboração de sua obra $O$ tupi na 
Geografia Nacional publicada em 1901, trabalho que ainda carece de uma interpretação geográfica e uma assimilação do seu valor para o campo disciplinar da Geografia.

Após pedir demissão por estar envolvido em algumas contendas que foram polemizadas em gazetas da capital paulista (LIMA, 1981), Theodoro Sampaio retornou para seu estado natal e estabeleceu residência em Salvador, cidade onde acabou exercendo novas ações relacionadas ao planejamento e execução de serviços voltados para a oferta de água e esgoto tratado na capital. Além disso, também participou da "reconstrução da Faculdade de Medicina, da nova fachada da igreja da Vitória e do Instituto Geográfico e Histórico da Bahia. Dirigiu a construção do Instituto Clínico, do pavilhão para tuberculosos do hospital Santa Isabel e do Liceu Salesiano de Salvador" (LIMA, 1981, p. 30).

Segundo leituras realizadas por Lima (1981), mesmo com estabelecimento do contrato entre Sampaio e o Conselho Municipal para execução de serviços de água e esgoto na cidade do Salvador, que deveria durar de 1905 a 1910, as ações se arrastaram por 14 anos. Havia um descontentamento manifestado pelo nosso personagem em cartas escritas tanto para Max Fleiuss quanto para Wanderley Pinho. A problemática se arrastou por anos, até o rompimento do contrato em 1929. Na cidade do Salvador, Theodoro Sampaio além de participar dessas questões que envolviam o abastecimento de água e as redes de esgoto, também se envolveu com atividades ligadas ao Instituto Geográfico e Histórico da Bahia, exercendo a presidência do principal congresso nacional de Geografia, em 1916, ocorrido na cidade do Salvador.

Neste evento, além exercer a presidência, também apresentou trabalhos técnico-científicos, como foram analisados por Vaz (2017). Alguns anos antes deste certame, retornou a São Paulo para receber uma premiação no IHGSP, uma medalha de prata "conferida pela Academia de História Internacional da França" (LIMA, 1981, p. 33).

Retomando as questões sobre planejamento urbano e regional, Sampaio também realizou duas contribuições em formatos de projeto para a cidade do Salvador, o primeiro foi a proposta do túnel do Carmo, que na atualidade denomina-se Américo Simas, responsável por fazer a ligação entre as 
principais avenidas de vale da cidade com o seu porto (Nazaré, Aquidabã e Sete Portas com Calçada e Comércio), o segundo foi os "Estudos e Projetos para a Cidade Nova: A Cidade Luz", este como uma proposta de urbanização planejada de um trecho leste do litoral da cidade, em terras pertencente a Manoel Dias da Silva, a área atualmente compreende o bairro da Pituba.

Como se pode verificar, as contribuições de Theodoro Sampaio para a urbanização da cidade do Salvador também se constituem como elementos importantes para serem analisados. Pensamos em propor uma análise futura acerca da materialização dos seus planos relativos ao planejamento urbano e regional, com vistas a desenhar uma geografia histórica desses lugares por quais o engenheiro-geógrafo transitou. Ainda em tempo, destacamos sua presidência do IGHB iniciada em 22 de outubro de 1922, com apoio de uma das principais figuras, Bernardino de Souza, e sua entrada no campo político como deputado federal.

No mais, se tornou sócio correspondente do Instituto Histórico e Geográfico Brasileiro (IHGB), em 1902, para galgar posteriormente o cargo de honorário em 1916, notadamente no mesmo ano que exerce a presidência do $5^{\mathrm{o}}$ Congresso Brasileiro de Geografia. Também se tornou sócio correspondente da Associação de Geógrafos Brasileiros (AGB), logo após a instalação das universidades e criação dos cursos superiores de Geografia no Brasil durante a década de 1930 (SEABRA, 2008).

Como apontado por Lima (1981), esta última participação no IHGB, garante uma nova rede de relações, com intelectuais como historiador Capistrano de Abreu, que reconhece como de forma "assombrosa" as interpretações de mapas e roteiros antigos da Bahia realizados por Theodoro, assim como seu talento como exímio topógrafo (ABREU, 1954 apud LIMA, 1981). Sua trajetória se encerra aos 82 anos de idade em 15 de outubro e 1937, em uma casa no bairro das Laranjeiras no Rio de Janeiro.

O momento da trajetória deste personagem em Salvador, como já apontado, suscita possibilidades investigativas, que podem abarcar não só as suas ações e produções, mas também seu envolvimento dentro de um contexto amplo que são as transformações urbanísticas sofridas pela cidade no primeiro 
quartel do século XX. Portanto, atentar para essas questões em relação ao papel de Theodoro Sampaio, pode trazer um conhecimento enriquecido da magnitude das suas obras e da sua importância contextual.

Só para ter uma aproximação inicial, arrolaremos aqui algumas obras que podem ser visitadas e que a partir delas podem ser realizadas leituras geográficas que façam sentido à História da Geografia e do Pensamento Geográfico no Brasil, portanto são: A planta geral da cidade do Salvador (1916a); Carta da Bahia de Todos os Santos (1916b); Movimentos sísmicos na Bahia de Todos os Santos (1916c); Do estudo e cadastro da força hidráulica dos rios brasileiros e da nacionalização de suas águas (1916d); Inscrições lapidares indígena do Vale do Paraguassú (1918a); Relatório dos estudos e projetos para uma cidade nova (A cidade luz) (1919); Viagem a Serra da Mantiqueira, Campos do Jordão e São Francisco dos Campos (1978); O tupi na Geografia Nacional (1987); História da fundação da cidade do Salvador (2016 - obra póstuma e inacabada) entre outras publicações em jornais, periódicos, relatórios, cartas e o seu próprio diário que podem servir de material de pesquisa para uma leitura geográfica ${ }^{4}$.

\section{CONSIDERAÇÕES FINAIS}

Ao listarmos no tópico anterior algumas das obras produzidas por Sampaio, observamos a magnitude da sua contribuição para o campo científico da Geografia, mesmo sendo um engenheiro civil formado pela Escola Central do Rio de Janeiro no século XIX. Mesmo com tal formação especializada, Theodoro Sampaio conseguiu ultrapassar a sua área de formação e realizar contribuições significativas para outros campos científicos. Podemos aqui traçar um paralelo entre ele e Barão do Rio Branco, este personagem muito importante para resolução de litígios internacionais que envolviam o Brasil, assim como a formação das atuais fronteiras. Na ótica de Moraes (2015), Rio Branco era um geógrafo refinado, do ponto de vista da história da ciência, e também um construtor prático de territórios, ao se olhar pela ótica da geografia política. Então, como podemos conceber Theodoro Sampaio dentro da Geografia?

\footnotetext{
${ }^{4}$ Alguns trabalhos citados já foram explorados em Vaz (2017), mas atentamos para o fato que existem outras possibilidades de leituras além das quais realizadas por esta autora.
} 
Propomos concebê-lo como um geógrafo planejador urbano e regional ao pensar e desenvolver obras para os espaços paulistano e baiano dentro das diretrizes que viria a inserir essas cidades dentro da modernidade capitalista ou como aquele geógrafo que sistematizou informações sobre os sertões. Apresentamos ao longo desse texto aspectos para se pensar a contribuição de Sampaio para o campo geográfico e como uma leitura das suas produções técnico-científicas a partir de um sentido para a Geografia se faz necessário. Atentamos para o fato que o nosso objetivo aqui era realizar um esboço capaz de traçar aspectos fundamentais para se iniciar essa leitura, realizando assim um exercício narrativo de perceber os fragmentos do passado a partir de uma ótica do presente, pensamos assim ter cumprido nosso intento neste momento.

\section{REFERÊNCIAS}

ANTUNES, Willian. Um modelo de resenha por Camille Vallaux. GEOgraphia, Niterói, v. 19, n. 39, p. 95-102. jan./abr. 2017.

AZEVEDO, Fernando de (org.). As ciências no Brasil. Rio de Janeiro: Ed.UFRJ, 2 v, 1994. 399p.

BAUMGaRTNER, Wendel Henrique. A Geografia das Cidades em Bernardino José de Souza. Influência alemã e conhecimento local nas monografias descritivas do estado da Bahia. Terra Brasilis (Nova Série). Revista da Rede Brasileira de História da Geografia e Geografia Histórica, Rio de Janeiro, n. 8, 2017. Disponível em: http://terrabrasilis.revues.org/1993. Acesso em: 20 junho 2017.

BENJAMIN, Walter. Obras escolhidas I: magia e técnica, arte e política. São Paulo: Brasiliense, 1996. 253p.

BERDOULAY, Vincent. A abordagem contextual. Espaço e Cultura, n.16, p.47-56. jul./dez. 2003.

BOURDIEU, Pierre. Usos sociais da ciência. São Paulo: Editora da Unesp, 2004. 88p.

CAPEL, Horácio. Geografia contemporânea: ciência e filosofia. Maringá: Eduem, 2010. 169p.

CAPEL, Horácio. 0 nascimento da ciência moderna e a América. 0 papel das comunidades científicas, dos profissionais e dos técnicos no estudo do território. Maringá: Eduem, 1999. 198p.

CARDOSO, Luciene Pereira Carris. Intelectuais, militares, instituições na configuração das fronteiras brasileiras (18831903). São Paulo: Alameda, 2016. 189p.

CARDoso, Luciene Pereira Carris. Meio século de Congressos Brasileiros de Geografia. Impressões de uma releitura. Terra Brasilis (Nova Série). Revista da Rede Brasileira de História da Geografia e Geografia Histórica, Rio de Janeiro, n. 8, 2017. Disponível em: http://terrabrasilis.revues.org/1975. Acesso em: 20 junho 2017.

CARDOSO, Luciene Pereira Carris. 0 Lugar da Geografia Brasileira: a sociedade de Geografia do Rio de Janeiro entre 1883 e 1945. São Paulo: AnnaBlume, 2013. 240p. 
CLAVAL, Paul. Como construir a história da geografia?. Terra Brasilis (Nova Série). Revista da Rede Brasileira de História da Geografia e Geografia Histórica, Rio de Janeiro, n. 2, 2013. Disponível em: https://terrabrasilis.revues.org/637. Acesso em: 20 junho 2017 .

CLAVAL, Paul. Terra dos Homens: a Geografia. São Paulo: Contexto, 2010. 144p.

COSTA, Ivoneide de França. o rio São Francisco e a chapada Diamantina nos desenhos de Teodoro Sampaio. $2007.176 \mathrm{f}$. Dissertação (Mestrado em Ensino de Filosofia e História das Ciências) - Universidade Estadual de Feira de Santana.

COSTA, Luís Augusto Maia. o ideário urbano paulista na virada do século. 0 engenheiro Theodoro Sampaio e as questões territoriais e urbanas modernas. 2001. Dissertação (Mestrado em História e Fundamentos da Arquitetura e Urbanismo) Faculdade de Arquitetura e Urbanismo, Universidade de São Paulo.

COSTA, Luiz Augusto Maia. Theodoro Sampaio, o Código Sanitário do Estado de São Paulo de 1894 e as exigências da modernidade. Risco: Revista de Pesquisa em Arquitetura e Urbanismo (Online), São Paulo, v. 14, n. 2, p. 15-22. jul./dez. 2016.

GUIMARÃES, Lúcia Maria Paschoal. Debaixo da imediata proteção imperial: Instituto Histórico e Geográfico Brasileiro. $2^{\text {a }}$ Ed. São Paulo: Annablume, 2011. 180p.

LIMA, Arnaldo do Rosário. Teodoro Sampaio: sua vida e sua obra. 1981. 146f. Dissertação (Mestrado em Ciências Sociais) Faculdade de Filosofia e Ciências Sociais, Universidade Federal da Bahia.

LIRA, Larissa Alves de. 0 primeiro esboço do método geográfico de Vidal de La Blache a partir dos estudos do Mediterrâneo. Permanências e rupturas no contexto da institucionalização da geografia (1872-1918). 2012. $227 f$. Dissertação (Mestrado em Geografia) - Faculdade de Filosofia e Ciências Humanas, Universidade de São Paulo.

LUCIO, Silvana T. M. Pettinato. João Pedro Cardoso e a ação da Comissão Geográfica e Geológica na apropriação e produção do território paulista 1905-1931. 2014. 241f. Tese (Doutorado em Arquitetura e Urbanismo) - Faculdade de Arquitetura, Universidade de São Paulo.

MACHADO, Lia Osório. As idéias no lugar. O desenvolvimento do pensamento geográfico no Brasil no início do século XX. Terra Brasilis (Nova Série). Revista da Rede Brasileira de História da Geografia e Geografia Histórica, Rio de Janeiro, n. 2, 2000. Disponível em: < http://terrabrasilis.revues.org/298 $>$. Acesso em: 18 agosto 2016.

MACHADO, Lia Osório. Origens do pensamento geográfico no Brasil: meio tropical, espaços vazios e a idéia de ordem (18701930). In: CASTRO, Iná Elias; GOMES, Paulo César da Costa; CORRÊA, Roberto Lobato (orgs). Geografia conceitos e temas. Rio de Janeiro: Bertrand Brasil, 1995. p. 309-353.

MARY, Cristina Pessanha. Geografias Pátrias: Portugal e Brasil - 1875/1889. Niterói: Editora da UFF, 2010. 192p.

MORAES, Antonio Carlos Robert. Notas sobre identidade nacional e institucionalização da geografia no Brasil. Revista Estudos Históricos, v. 4, n. 8, p. 166-176. jul./dez. 1991.

MORAES, Antonio Carlos Robert. O Barão do Rio Branco e a geografia. Terra Brasilis (Nova Série). Revista da Rede Brasileira de História da Geografia e Geografia Histórica, Rio de Janeiro, n. 5, 2015. Disponível em: http://terrabrasilis.revues.org/1546. Acesso em: 5 agosto 2016.

MORAES, Antonio Carlos Robert. Ideologias geográficas. São Paulo: Annablume, 2005a. 156p.

MORAES, Antonio Carlos Robert. Território e história no Brasil. São Paulo: Annablume, 2005b. 198p. 
MOREIRA, Helói José Fernandes. Formar bacharéis ou engenheiros, um dilema da Escola Central. In: Livro de Anais do Congresso Scientiarium história IV. Vol. 1, Fascículo 1. Rio de Janeiro: Editora da UFRJ, 2011, p. 354-360.

OLIVEIRA, Vanderlí Fava de. Crescimento, evolução e o futuro dos cursos de engenharia. Revista de Ensino de Engenharia, v. 24, n. $2,2008$.

PEREIRA, Sergio Nunes. Histórias do pensamento geográfico. Instituições, institucionalização e produção do conhecimento. Terra Brasilis (Nova Série). Revista da Rede Brasileira de História da Geografia e Geografia Histórica, Rio de Janeiro, n. 2, 2000. Disponível em: http://terrabrasilis.revues.org/316. Acesso em: 5 agosto 2016.

PRADO JÚNIOR, Caio. História econômica do Brasil. São Paulo: Brasiliense, 2008. 365p.

RAMOS, Cleidiana. Diários revelam memória de Theodoro Sampaio. A Tarde. 20 de set. 2015. Disponível em: http://atarde.uol.com.br/bahia/salvador/noticias/1713589-diarios-revelam-memoria-de-theodoro-sampaio-premium . Acesso em: 12 setembro 2017 .

SÁ, Dominchi Miranda de. A ciência como profissão: médicos, bacharéis e cientistas no Brasil (1895-1935). Rio de Janeiro: Editora Fiocruz, 2006. 216p.

SANTANA, José Carlos Barreto de. Geologia e metáforas geológicas em Os sertões. Revista História, Ciências, Saúde Manguinhos, Rio de Janeiro, v. 5, p. 117-132. Jul. 1998.

SANTOS, Ademir Pereira dos. Theodoro Sampaio: nos sertões e nas cidades. Rio de Janeiro: Versal, 2010. 391p.

SCHWARCZ, Lilia Moritz. 0 espetáculo das raças: cientistas, instituiȩões e questão racial no Brasil do século XIX. São Paulo: Editora Companhia das Letras, 1993. 296p.

SAMPAIO, Theodoro. A planta geral da cidade do Salvador da Bahia de Todos os Santos. In: Annaes do $5^{o}$ Congresso Brasileiro de Geografia, v. I, Salvador: Instituto Geográfico e Histórico da Bahia, 1916a, p. 55-61.

SAMPAIO, Theodoro. A carta-hydrografica da Bahia de Todos os Santos e de seus arredores. In: Annaes do $5^{\text {o Congresso }}$ Brasileiro de Geografia, v. I. Salvador: Instituto Geográfico e Histórico da Bahia, 1916b, p. 101-115.

SAMPAIO, Theodoro. Movimentos sismicos na Bahia de Todos os Santos. In: Annaes do 5o Congresso Brasileiro de Geografia, v. I. Salvador: Instituto Geográfico e Histórico da Bahia, 1916c, p. 355-368.

SAMPAIO, Theodoro. Do estudo e cadastro da força hydraulica dos rios brasileiros e da nacionalisação de suas águas. In: Annaes do $5^{o}$ Congresso Brasileiro de Geografia, v. I. Salvador: Instituto Geográfico e Histórico da Bahia, 1919d, p. 395420 .

SAMPAIO, Theodoro. Inscrições lapidares indígenas no Vale do Paraguassu. In: Annaes do $5^{\text {o }}$ Congresso Brasileiro de Geografia, v. II. Salvador: Instituto Geográfico e Histórico da Bahia, 1918a, p. 6-32.

SAMPAIO, Theodoro. Denominações geográficas indígenas em torno da Bahia de Todos os Santos . In: Annaes do $5^{\text {o }}$ Congresso Brasileiro de Geografia, v. II. Salvador: Instituto Geográfico e Histórico da Bahia, 1918b, p. 143-158.

SAMPAIO, Theodoro. Relatório dos estudos e projetos para uma cidade nova (A Cidade Luz), na Pituba, nos terrenos de propriedade do Sr. Manoel Dias da Silva, pelo engenheiro civil Theodoro Sampaio. Salvador: Imprensa Official do Estado da Bahia. Instituto Geográfico e Histórico da Bahia, Arquivo Histórico Theodoro Sampaio, 1919.

SAMPAIO, Theodoro. Viagem a Serra da Mantiqueira, Campos do Jordão e São Francisco dos Campos. Brasiliense: Sao Paulo, 1978, 57p. 
SAMPAIO, Theodoro. O tupi na geografia nacional. São Paulo: Editora Nacional, 1987. 360p.

SAMPAIO, Theodoro. História da fundação da cidade do Salvador. Salvador: Assembleia Legislativa, 2016.494 p.

SEABRA, M. Caio Prado Jr. e os Primeiros Anos da AGB: Descrição comentada e estudo introdutório de documentos diretamente relacionados à Associação dos Geógrafos Brasileiros, do Dossiê AGB do Acervo Caio Prado Jr., do IEB-USP. In: IUmatti, P.; SEABRA, M; HeIdemann, H. D. (Org.). Caio Prado Junior e a Associação dos Geógrafos Brasileiros. São Paulo. EDUSP, 2008. 357p. p. 13-125.

SEVCENKO, NICOLAU. O outono dos césares e a primavera da história. Revista USP, n. 54, p. 30-37, 2002.

SILVA, Tereza Cardoso Encontros com Milton Santos. In: SILVA, M. A. (Org.). 10 anos sem Milton Santos. Salvador, ALBA, 2011.

SILVA, Maria Auxiliadora da; GONÇALVES, Neyde Maria Santos. Contribuições do Professor Tricart à Geografia da Bahia. In: SILVA, T. C (Org.). Da teoria à prática da Geografia global: abordagens transdisciplinar proposta por Jean Tricart. Santa Catarina Ed. GCN/CFH/UFSC, 2011.

SILVA, Aldo José Morais. INSTITUTO HISTÓRICO E GEOGRÁFICO DA BAHIA: Origem e estratégias de Consolidação Institucional 1894 - 1930. 2006. 249f. Tese (Doutorado em História) - Universidade Federal da Bahia.

SOUSA NETO, Manoel Fernandes de. As Outras Histórias ou da Necessidade Delas. Terra Brasilis, Rio de Janeiro, n. 2 , p. 137-145, 2000. Disponível em: http://terrabrasilis.revues.org/321. Acesso em: 10 agosto 2016.

SOUSA, André Nunes de. Percurso historiográfico do campo disciplinar geográfico na Bahia e em São Paulo: contribuições da Universidade Federal da Bahia e da Universidade de São Paulo. 2015. 236f. Tese (Doutorado em Geografia) - Instituto de Geociências, Universidade Federal da Bahia.

SOUSA, André Nunes de. Centralidades regionais, centralidades acadêmicas: reconfigurações territoriais no Brasil e suas influências no desenvolvimento da Geografia na Bahia (1870-1970). GeoTextos, Salvador, v. 12, n. 2, 2016. Disponível em: https://portalseer.ufba.br/index.php/geotextos/article/view/17055. Acesso em: 1 dezembro 2016.

SOUSA, André Nunes de. Bernardino de Souza e o desenvolvimento da Geografia no Brasil. Passagens do $5^{0}$ Congresso Brasileiro de Geografia. Terra Brasilis (Nova Série). Revista da Rede Brasileira de História da Geografia e Geografia Histórica, Rio de Janeiro, n. 8, 2017a. Disponível em: http://terrabrasilis.revues.org/1980. Acesso em: 9 julho 2017.

SOUSA, André Nunes de. História da Geografia na Bahia: do Período Regencial à República. Terra Brasilis (Nova Série). Revista da Rede Brasileira de História da Geografia e Geografia Histórica, Salvador, n. 8, 2017b. Disponível em: https://terrabrasilis.revues.org/2213. Acesso em: 17 julho 2017.

VARGAS, Héctor Mendoza. Francia y los ingenieros geógrafos de México, siglo XIX. In: BERDOULAY, Vicent; VARGAS, Héctor Mendoza (orgs). Unidad y diversidad del pensamento geográfico en el mundo. Retos y perspectivas. Cidade do México: UNAM, 2003. 340p. p. 103 - 115.

VAZ, Caroline Bulhões Nunes. Entre o sertão e a nação. Memórias de Theodoro Sampaio no $5^{\circ}$ Congresso Brasileiro de Geografia. Terra Brasilis (Nova Série). Revista da Rede Brasileira de História da Geografia e Geografia Histórica, Rio de Janeiro, n. 8, 2017. Disponível em: http://terrabrasilis.revues.org/1981. Acesso em: 20 setembro 2017. 